\title{
GRADUATES OF 2-YEAR ENGINEERING AND ENGINEERING TECHNICIAN PROGRAMMES IN THE U.S. AND THE U.K.
}

\author{
Reys-Nickel, L. ${ }^{1}$ \& Lasonen, J. $^{2}$ \\ ${ }^{1,2}$ Department of Leadership, Counselling, Adult, \\ Career and Higher Education, \\ Tampa, U.S.A.
}

Correspondence author email: lynsey.reys@gmail.com

Received October 19 $9^{\text {th }}, 2017$; Accepted January $22^{\text {nd }}, 2018$

\begin{abstract}
In the U.S. and the U.K., the demand for a skilled and educated workforce of engineers and engineering technicians is greater than the supply. Postsecondary institutions in the U.S. awarding associate's degrees in engineering and engineering technologies will fail to keep pace with job growth projections if trends of low and slow graduation rates continue. The purpose of this study was to identify the characteristics of attendees and graduates of associate's degree programmes in engineering and engineering technologies and determine whether and to what extent graduation is a function of student-related and institutional variables. Researchers used an ex post facto design using the 2004/2009 Beginning Postsecondary Students Longitudinal Study (BPS:04/09) dataset from the U.S. Department of Education's National Center for Education Statistics (NCES). Descriptive statistics indicated graduates were mostly White, married, middle income, employed part-time, enrolled full-time, completed Trigonometry/Algebra II, had a father who's highest education level was an associate's degree, did not know their mother's highest level of education, completed remedial coursework, and started college with the goal of an associate's degree. Logistic regression results indicated that gender and enrollment size during the 2003-2004 academic year significantly predicted associate's degree completion in engineering and engineering technologies. This study provided a current description of students pursuing sub-baccalaureate engineering and engineering technologies programmes in the U.S.. However, given the small weighted sample size, the regression was inconclusive in terms of the model's predictive ability. Therefore, future caution should be taken when analysing national, educational datasets to address national workforce shortages.
\end{abstract}

Keywords: Engineering technologist, STEM, logistic regression, predictors of success

DOI: https://10.30880/jtet.2018.10.01.003

Vol. 10, No.1 $\quad$ June 2018| ISSN 2229-8932 Journal of Technical Education and Training (JTET) | 30 


\section{INTRODUCTION}

Worldwide there is a shortage of engineers and engineering technicians. In the U.S. and the U.K., the demand for a skilled and educated workforce of engineers and engineering technicians is greater than the supply. Not only are there demands to fill newly created positions in the engineering sector, but there is also a need to fill existing vacancies that require a subbaccalaureate degree at a minimum (Carnevale, Smith, \& Melton, 2011).

\subsection{The demand for engineering and engineering technicians in the U.K.}

The U.K. and the U.S. exhibit similar economic output structures where in the U.K., 78\% of the economic output consists of services, $11 \%$ in manufacturing, $11 \%$ other industry, and less than $1 \%$ agriculture (Harrison, 2012). Out of a total working population of 30 million in the U.K., 3.2 million or $11 \%$ have an engineering skills base and can be found in every sector in the economy (Harrison, 2012). However, just as in the case of the U.S., the demand for engineers and engineering technicians in the U.K. is greater than the supply. From 2010-2020, the forecasted demand of new and replacement jobs in the U.K. for Science, Engineering, \& Technology Professionals will be 830,000 and Technicians will be 450,000 . The largest proportions of openings according to engineering discipline will be found in Construction (27.3\%) and Information \& Communications (23.7\%). Yet, compared to a 5\% average across the U.K. economy, $12 \%$ of vacancies in IT \& Telecommunications sectors, $11 \%$ in Energy and other utilities, and $11 \%$ in Construction went unfilled in 2013/2014 (Royal Academy of Engineering, 2016). Each year these vacancies are going unfulfilled, and thus demand continues to climb.

According to the Royal Academy of Engineering, the U.K. must graduate more than twice as many students, at least 1 million, in engineering and engineering technician programmes (Harrison, 2012). Specifically, workers holding Level 3 credentials under the Regulated Qualification Frameworks (RQF) and Framework for Higher Education Qualifications (FHEQ) needed per year thru 2022 are estimated at 60,000 (Ministry of Defense, 2017). Workers at Level 3 hold a qualification such as: Advanced Apprenticeship, National Vocational Qualification (NVQ) Level 3, Advanced Subsidiary \& Advanced Level (AS and A), BTEC National, AS and A Level, Cambridge Technical Level 3, or Key Skills Level 4. However, there are only 27,000 new entrants to engineering jobs with Level 3 qualifications.

At least 107,000 workers will be needed with Level 4 credentials, specifically those that completed VET programs issuing a National Vocational Qualifications (NVQ) Level 4, Higher Apprenticeship, Higher National Certificate (HNC), Key Skills Level 4, and BTEC Professional award, certificate, and diploma, or workers with higher education coursework or degrees (Ministry of Defense, 2017). It is estimated that the number of workers with Level 4+ qualifications needed per year through 2022 are 107,000, yet there are only 66,391 people entering engineering jobs at Level $4+$.

The U.K. must graduate at least 1 million new graduates from tertiary engineering \& engineering technologies programs, but there is a trend in the decline of Level 3 starters and graduates (Grant, 2015). Specifically, in further education in England, there was a 14.4\% decline in the number of new students for Level 3 Advanced Apprenticeships when comparing 2012/13 and 2013/14 (Ministry of Defense, 2017). In further education in Scotland, comparing the 
2012/13 and 2013/14 entering classes, the number of new female students in the engineering framework decreased by 64\% (Ministry of Defense, 2017). For higher education institutions across the U.K., comparing the number of applicants in 2011 and 2012 applications, Engineering saw a $2.6 \%$ decline and Technologies saw a $17.6 \%$ decline (Ministry of Defense, 2017). During this period, $5.9 \%$ of all male and $4.0 \%$ of female engineering and technology students did not continue with their studies (Ministry of Defense, 2017). Among all non-continuing students, approximately $7.2 \%$ of non-continuing students had no math or physics A levels (Ministry of Defense, 2017).

The same declining trend in enrolment and completion can be observed in England and Scotland. The number of new students in engineering-related Advanced Apprenticeship programs declined by 14\% in England when comparing the 2012/2013 and 2013/14 years (Ministry of Defense, 2017). New female students in the engineering framework in Scotland declined by $64 \%$ during the same period (Ministry of Defense, 2017). Not suprisingly, given the lower number of new students, there were shortages of 27,000 workers entering the engineering profession with Level 3 credentials and 40,000 engineering professionals with Level 4+ (Ministry of Defense, 2017).

\subsection{The demand for engineering and engineering technicians in the U.S.}

In the U.S. alone, projected job openings for engineers between 2014-2024 is 510,900, and the number of job openings for engineering technicians is 147,500 (Fayer, Lacey, \& Watson, 2017). According to discipline, the demand for technicians of wind turbines (a type of sustainable or renewable energy engineering) is expected to grow by at least $108 \%$. Related, the demand for petroleum technicians is expected to increase by $12 \%$ and demand for environmental engineering technicians is $10 \%$, both faster than the average job growth for all other occupations. Employment growth projections for engineering technicians in several disciplines through 2020 are as high as 30 percent, surpassing all other occupations (U.S. Department of Labor, 2014). Of the new and replacement engineering and engineering technologies jobs in the U.S., at least $25 \%$ will require an associate's degree (Carnevale et al., 2011; Carnevale, Smith, \& Strohl, 2010). This represents the largest proportion of any of the five STEM (Science, Technology, Engineering, and Mathematics) occupational subgroups requiring an associate's degree in the U.S.

Providers of engineering education and training in the U.S. include associate's colleges, baccalaureate/associate's colleges, baccalaureate colleges, master's colleges and universities, doctoral universities, special focus institutions, and tribal colleges and universities (Carnegie Classification of Institutions of Higher Education, 2017). Postsecondary institutions in the U.S. that award associate's degrees in engineering and engineering technologies will fail to meet job growth projections if trends of low and slow graduation rates continue. Comparing the 20002001 and 2010-2011 academic years, engineering and engineering technologies associate's degree conferrals declined by $16 \%$ while other subject areas doubled their number of associate's degree recipients (Aud, Rathburn, Flicker-Wilkinson, Krisapovich, Wang, \& Zhang, 2013). Even more drastic was the overall drop in the number of female graduates from engineering and engineering technologies programmes (25.3\%) (Planty, Hussar, Snyder, Kena, KewalRamani, Kemp, Bianco, \& Dinkes, 2009). There is clearly a need to understand more comprehensively the issue of low completion rates in engineering and engineering technologies programmes. 


\subsection{Purpose and research questions}

Data on STEM education and the engineering workforce are often presented too broadly to positively affect reform and acute employment deficits (Hagedorn \& Purnamasari, 2012). Hagedorn and Purnamasari (2012) maintained that what is missing from previous scientific attempts is a disaggregation of student background information following the identification of specific STEM-occupational shortages. The purpose of this paper is to identify the characteristics of attendees and graduates of 2-year, associate's degree programmes in engineering and engineering technologies using a national dataset and determine whether and to what extent graduation from these programs is a function of specific student-related variables and institutional variables. The following research questions were pursued: (1) What are the characteristics of completers and non-completers of sub-baccalaureate degree programs in engineering and engineering technologies in the U.S.? (2) To what extent do student-related and institutional variables predict completion in sub-baccalaureate degree programs in engineering and engineering technologies in the U.S.?

\subsection{Theoretical framework}

The theoretical framework for the study is an integration of two major theoretical strands: Tinto's Student Integration Model and Astin's "Input-Environment-Outcome" (I-E-O) Model. Tinto (1993) described the behaviors of completion and attrition as a longitudinal decisionmaking process influenced by student and institutional characteristics. Tinto (1993) described completion and attrition as a longitudinal decision-making process influenced by student's demographic and pre-college attributes, finances, goals and commitments, institutional experiences, and integration (Tinto, 1993). Astin (1991) suggested an approach to examining student outcomes in which student outcomes are a direct function of inputs and inputs plus the environment. Known as the "Input-Environment-Outcome" (I-E-O) Model, the "I" in the I-E-O Model stands for Inputs that are the student's personal qualities that he or she enters the educational context with and would be used in research studies as an independent variable for those employing the Model (Astin, 1991). This includes the same student variables described by Tinto (1993) (i.e., demographic background, academic performance [past and present], and precollege experiences). "E" is the Environment, and as is the case with Tinto's theory and institutional variables, examples of "E" include student and faculty population demographics, academic and social programs, and institutional and programmatic characteristics or variables. Lastly, "O" or Outcomes, are the intended "talents" that the institution or program wants to develop or influence (i.e., college completion) (Astin, 1991). Omitting one of the three constructs in research renders the model incomplete, generates results that are ambiguous, biased, or difficult to interpret, and subsequent policy and programmatic decisions are misinformed and ineffective (Astin, 1991). In the present examination, the researcher considered institutional characteristics along with student-related characteristics to predict the outcome of completion and non-completion in sub-baccalaureate programs in engineering and engineering technologies. 


\section{METHODOLOGY}

The quantitative study is an ex post facto design using secondary data from the U.S. Department of Education's National Center for Education Statistics (NCES) 2004/2009 Beginning Postsecondary Students Longitudinal Study (BPS:04/09). BPS: 04/09 provided nationally representative samples of the subpopulations of interest, in this case engineering and engineering technologies students, from which findings are highly generalizable (Greenhoot \& Dowsett, 2012). BPS: $04 / 09$ starts with a sample of 18,600 students who were interviewed at the end of their first year (2003-2004) in college in the National Postsecondary Study Aid Study (NPSAS). They were subsequently interviewed three- (2005-2006) and six-years (2008-2009) later. Data were concluded as reliable after random sample major/field of study data were recoded. The BPS:04/09 public-use dataset accessible in PowerStats (a web-based analytical tool on the NCES website) includes 16,680 study respondents and 1,500 variables. For the purposes of this study the target population was students in sub-baccalaureate STEM-degree programmes. In this study, the BPS: 04/09 weighted student sample was reduced to 93 weighted participants of associate's degree programmes in engineering and engineering technologies. In accordance with NCES's standards to minimize the disclosure risk of personally identifiable data, the absolute sample size was modified through coarsening and weighting and was not disclosed.

The student-related and institutional variables referenced in the literature and Tinto's and Astin's theories on graduation were explored. Student-related, independent variables included: 1) age first year enrolled, 2) grade point average 2003-04, 3) grade point average estimate when last enrolled thru 2009, 4) gender, 5) race/ethnicity, 6) marital status, 7) income group 2003-04, 8) job while enrolled 2004, 9) father's highest level of education 2003-04, 10) mother's highest level of education 2003-04, 11) high school type attended, 12) highest level of high school mathematics, 13) degree goal, 14) attendance intensity pattern through 2009, 15) remedial course 2004, and, 16) aid package by type of aid 2003-04. Institutional, independent variables included: 1) total enrollment size 2003-04, 2) percent minority enrollment 2003-2004, and, 3) institution region 2003-04.

To answer the 1st research question, the researcher performed descriptive statistical analyses of student-related variables in PowerStats. Broene and Rust (2000) do not recommend the use of PAWS Statistics (formerly known as SPSS) and SAS software packages for complex survey data such as the BPS because, "they are based on the assumption of independent, identically distributed observations, or simple random sampling with replacement," (p. 1). To identify the characteristics of completers, in PowerStats, the independent variables of gender, ethnic group, marital status, enrollment in any remedial coursework, income group, employment status, and father's and mother's highest educational level and the dependent variable of associate's degree attainment (which were identified in the literature and theoretical framework as potential influencers) were selected. The filter function limited results to students that attained associate's degrees in engineering and engineering technologies programs. To identify the characteristics of non-completers, the dependent variable was replaced with students that did not attain an associate's degree. Independent variables remained the same. The researcher then used a Filter function to limit results to students that enrolled in the engineering and engineering technologies programs. 
To answer the 2nd research question logistic regression was performed in PowerStats. The researcher used PowerStats to regress the criterion variable on the following predictor variables: age first year enrolled, gender, race/ethnicity, grade point average 2003-04, grade point average estimate when last enrolled thru 2009, remedial course 2004, income group 200304, high school type attended, highest level of high school mathematics, job while enrolled 200304, enrollment size 2003-04, and percent minority enrollment 2003-04. The dependent variable was associates degree completion in engineering and engineering technologies.

\section{RESULTS}

Descriptive statistics in the form of averages and percentage distributions described the studentrelated characteristics of completers and non-completers of associate's degree programs in engineering and engineering technologies. Wald statistics indicated the variables that significantly predicted associate's degree completion in engineering and engineering technologies. Odds ratio results identified the variables statistically significant to the model. Likelihood ratios for the regression to predict the completion of engineering and engineering technologies associate's degrees were generated.

\subsection{Averages of attendees in associate's degree programs in engineering and engineering technologies}

Among completers of engineering and engineering technologies associate's degree programs, the average age upon entering college during the 2003-2004 academic year was 22 years, while the average age of six-year engineering and engineering technologies completers was 21.2 years. For non-completers of engineering and engineering technologies associate's degree programs, the average age when starting college was 21.3 years, which was younger than the age of completers.

\subsection{Outcomes by student demographics}

A majority of attendants of associate's degree programs in engineering and engineering technologies were male $(90 \%)$ with females in the minority at $10 \%$. While males attended the programs at a higher proportion than did females, completion rates were comparable. About $30 \%$ of both genders attained the degree during the study, while $70 \%$ did not complete the degree program.

White students made up $56.37 \%$ of all attendees in associate's degree programs in engineering and engineering technologies. Compared to all other racial/ethnic groups, Whites also had higher completion rates. About $40 \%$ completed the program and earned an associate's degree, while $60 \%$ did not complete the program. Although students of More than one Race made up only $4.31 \%$ of the total population of attendees, they had the second highest rate of completion at $27.79 \%$. The third highest rate of completion relative to the overall racial/ethnic population was students in the other category at $21.90 \%$. Students of Hispanic or Latino descent comprised the second highest racial/ethnic population of all attendees at $21.65 \%$. However, from the group of Hispanic or Latino students, only $21.02 \%$ completed the associate's degree program; whereas, 78.98\% were non-completers. Asians made up 3.41\% of all attendees with $18.91 \%$ completing and $81.09 \%$ not completing the degree program. Native Hawaiian/Pacific Islanders made up $0.28 \%$ of the total population, proportionally, and experienced the lowest rate 
of completion $(0.00 \%)$. In other words, no Native Hawaiian/ Pacific Islanders completed the associate's degree program in engineering and engineering technologies. Blacks or African Americans represented $11.68 \%$ of all attendees in the associate's degree programs in engineering and engineering technologies with the second lowest rate of completion $(10.53 \%)$ and second highest rate of non-completion (89.47\%) compared to the other racial/ethnic groups.

As it pertains to student marital statuses when first enrolled, single, divorced, or widowed represented $90.32 \%$, married students comprised $9.27 \%$, and separated students made up $0.42 \%$ of all attendees in associate's degree programs in engineering and engineering technologies programs. Attendees who were married when they first began the program experienced higher rates of completion (42.93\%) than did attendees with other marital statuses. Among single, divorced, or widowed, over one-quarter or $27.65 \%$ attained the degree, while no attendees $(0.00 \%)$ with separated marital status earned the degree.

Slightly more than half $(51.57 \%)$ of all attendees in associate's degree programs in engineering and engineering technologies programs considered themselves middle income, while $31.66 \%$ responded as low income, and $16.76 \%$ self-identified as high income during the 20032004 academic year. Thirty-eight percent of the middle-income attendees completed the associate's degree program and $62 \%$ did not complete the program. Among low income attendees, twenty-four percent completed the associate's degree program, while $76 \%$ did not complete the program. Similarly, twenty-three percent of high income students completed the associate's degree program with $77 \%$ not completing.

Also, one-third (34.78\%) of all attendees in associate's degree programs engineering and engineering technologies programs were unemployed during the 2003-2004 academic year. Among those without employment, 24.94\% attained the degree and 75.06\% did not. Similarly, students with a part-time job comprised $36.29 \%$ of all attendees in associate's degree programs in engineering and engineering technologies programs with $35.51 \%$ earned the degree and $64.49 \%$ not completing the program. Finally, students with a full-time job represented $28.93 \%$ of all attendees. Approximately $31.78 \%$ of those students completed the associate's degree program and $68.22 \%$ failed to complete the program.

\subsection{Outcomes by parents' highest level of education attainment}

Attendees whose father's highest level of education was a high school diploma or equivalent made up $33.37 \%$ of all attendees in associate's degree programs in engineering and engineering technologies programs. Comparatively, students whose fathers did not complete high school represented the second highest proportion of attendees (14.01\%), followed by fathers with: a) a bachelor's degree $(11.77 \%)$, b) less than two years of college $(7.61 \%)$, c) a master's degree $(6.82 \%), d)$ vocational or technical training $(6.54 \%)$, e) associate's degree $(4.90 \%)$, (f) two or more years of college but no degree $(2.29 \%)$, g) doctoral degree or equivalent $(1.04 \%)$, and $h$ ) first-professional degree $(0.35 \%)$. It should be noted that $11.30 \%$ of attendees did not know their father's education level.

Among attendees whose fathers had an associate's degree, approximately $68.95 \%$ completed that degree in engineering and engineering technologies. The group with the second highest proportion of completers were attendees whose fathers earned a high school diploma or equivalent (38.85\%), followed by fathers who had: a) vocational or technical training $(37.58 \%)$, 
b) a bachelor's degree (34.19\%), c) an unknown education level $(29.62 \%)$, d) a doctoral degree or equivalent $(26.65 \%)$, e) less than a high school diploma $(23.46 \%)$, f) two or more years of college but no degree $(9.39 \%)$, g) a master's degree $(7.66 \%)$, and h) less than two years of college $(3.63 \%)$.

While the population of attendees whose father's highest level of education was the firstprofessional degree $(0.35 \%)$, they were also the group with the highest percent of noncompletion $(100 \%)$. The proportions of non-completing attendees, according to father's highest level of education, included: a) less than two years of college $(96.37 \%), b)$ a master's degree $(92.34 \%)$, c) two or more years of college but no degree $(90.61 \%)$, d) a doctoral degree or equivalent $(73.35 \%)$, e) an unknown education level $(70.38 \%)$, f) a bachelor's degree $(65.81 \%)$, g) vocational or technical training $(62.42 \%)$, h) a high school diploma or equivalent $(61.15 \%)$, and i) an associate's degree (31.05\%).

Similar to their father's information, students whose mother's highest level of education was a high school diploma or equivalent made up $36.99 \%$ of all attendees in associate's degree programs in engineering and engineering technologies. Comparatively, students whose mothers earned a bachelor's degree represented the second highest proportion of attendees (13.99\%), followed by attendees whose mothers did not complete high school (9.68\%), and the following: a) an associate's degree $(8.88 \%)$, b) less than two years of college $(7.63 \%)$, c) a master's degree $(6.76 \%), d)$ vocational or technical training $(5.42 \%)$, e) two or more years of college but no degree $(5.39 \%)$, f) a doctoral degree or equivalent $(0.69 \%)$, and g) a first-professional degree $(0.21 \%)$. Approximately $4.35 \%$ of attendees did not know their mother's education level. Coincidentally, this group of attendees also experienced the highest rate of completion (45.92\%). The group with the second highest proportion of completers had mothers that undertook vocational or technical training (42.53\%), followed by mothers with: a) a doctoral degree or equivalent $(39.98 \%)$, b) an associate's degree $(38.42 \%)$, c) a high school diploma or equivalent $(37.66 \%)$, d) non-completion of high school $(32.07 \%)$, e) a master's degree $(31.38 \%)$, f) a bachelor's degree $(19.79 \%), \mathrm{g})$ two or more years of college but no degree $(7.42 \%)$, and $\mathrm{h}$ ) less than two years of college (5.64\%).

The population of attendees whose mother's highest level of education was the firstprofessional degree $(0.21 \%)$ were also the group with the highest percent of non-completion (100\%), following by: a) less than two years of college $(94.36 \%)$, b) two or more years of college but no degree $(92.58 \%)$, c) a bachelor's degree (80.21\%), d) a master's degree $(68.62 \%)$, e) non-completion of high school $(67.93 \%)$, f) a high school diploma or equivalent $(62.34 \%), \mathrm{g}$ ) an associate's degree $(61.58 \%), \mathrm{h}$ ) a doctoral degree or equivalent $(60.02 \%)$, and i) vocational or technical training (57.47\%). The group with the lowest percentage of non-completion was among students who did not know the highest education level of their mother (54.08\%).

\subsection{Outcomes by high school enrolment type and highest high school mathematics level}

Of those enrolled in associate's degree programs in engineering and engineering technologies, a majority (82.25\%) attended a public high school, netting approximately $30.21 \%$ as completers and $69.79 \%$ as non-completers of the degree program. The $9.02 \%$ of attendees that did not possess a high school diploma or certificate also included the highest percentage of associate's degree completers $(43.97 \%)$. In other words, the group that did not possess a high school diploma or certificate experienced the lowest percentage of non-completion (56.03\%). 
Approximately $6.47 \%$ of students attended a private school of which $26.14 \%$ completed and $73.86 \%$ did not complete the associate's degree program. Attendees who went to a foreign high school comprised $2.25 \%$ of the total population. Close to $11 \%$ completed the associate's degree program; whereas, $90.09 \%$ did not, thereby generating proportionally the highest percentage of non-completion.

About one-third (30.29\%) stated the highest mathematics level they completed in secondary school was algebra 2 . The highest math levels completed by other attendees included pre-calculus $(21.35 \%)$, calculus $(19.30 \%)$, trigonometry/algebra II $(17.42 \%)$, or none of those types previously mentioned (11.64\%). Attendees who completed high school trigonometry/algebra II showed the highest percentage of completion of the associate's degree in engineering and engineering technologies (57.88\%). The lower percentages of completion were among attendees that completed types of high school mathematics not mentioned in the study (29.84\%), pre-calculus (28.66\%), algebra 2 (26.18\%), and calculus (16.09\%). Conversely, attendees that completed calculus as their highest level of high school mathematics experienced the highest rate of non-completion $(83.91 \%)$.

\subsection{Outcomes by postsecondary enrolment characteristics}

The bachelor's degree (65.63\%) was the most common degree goal among all attendees, followed by an associate's degree $(28.99 \%)$, a certificate $(3.42 \%)$, or no degree (1.96\%). However, the degree goal with the most completers, proportional to attendees, was an associate's degree $(43.84 \%)$, followed by the certificate $(27.01 \%)$, a bachelor's degree $(25.46 \%)$, and no degree $(22.03 \%)$.

Close to $60 \%$ of students noted they always attended the program on a full-time basis, $3.19 \%$ always attended part-time, and $37.57 \%$ attended on a mixed (full-time and part-time) basis. Students that attended on a full-time basis also experienced the highest percentage of completion $(41.32 \%)$, followed by mixed attendees $(16.70 \%)$. None of the students $(0.00 \%)$ that attended on an always part-time basis completed the degree program.

The majority of attendees (83.53\%) in associate's degree programs in engineering and engineering technologies that did not need remedial coursework. Of the attendees in this category, there were fewer completers $(29.12 \%)$ than non-completers $(70.88 \%)$. Conversely, there was a higher percentage of completers of the associate's degree program $(39.03 \%)$ among the $16.47 \%$ attendees that did need remedial coursework.

Attendees that received financial aid in the form of grants and loans during the 20032004 academic year represented $27.86 \%$ of the total population of attendees in the associate's degree program in engineering and engineering technologies. The remaining proportion of students received aid packages consisting of: a) no aid $(24.32 \%)$, b) grants only $(22.48 \%)$, c) grants, loans, and other $(8.53 \%)$, d) loans only $(5.12 \%)$, e) loans and other $(2.90 \%)$, f) grants, loans, and work-study $(2.47 \%)$, g) grants and other $(1.71 \%)$, h) grants and work-study $(1.48 \%)$, i) grants, loans, work-study, and other $(1.04 \%)$, j) work-study and other $(0.80 \%)$, k) other $(0.74 \%)$, and 1$)$ work-study only $(0.55 \%)$. Of those attendees, those receiving work-study and other aid packages reported the highest percentage of completion $(100 \%)$. On the other hand, attendees that received work-study only and those with grants, loans, work-study, and other aid packages reported the highest percentages of non-completion. Attendees that received loans and 
other also demonstrated higher percentages of completion $(68.95 \%)$ than did those with: a) other only $(62.48 \%)$, b) grants, loans, and other $(48.95 \%)$, c) grants and loans $(33.73 \%)$, d) loans only $(31.17 \%)$, e) no aid $(28,92 \%)$, f) grants and work-study $(20.71 \%)$, g) grants only $(19.40 \%), \mathrm{h})$ grants, loans, and work-study (16.14\%), and i) grants and other $(10.80 \%)$.

\subsection{Predictors of associate's degree completion in engineering and engineering technologies}

To analyze the effects of the predictor variables on the second criterion variable in the study, the criterion variable Transcript: First Associate's degree field of study: 2-digit CIP was regressed in PowerStats on the predictor variables. In order to analyze the relationship of the independent variables on the dependent variable, the dependent variable and the following independent variables inputted into PowerStats: a) age, b) gender, c) race/ethnicity, d) grade point average 2003-04, e) grade point average estimate thru 2009, f) remedial course 2004, g) income group 2003-04, h) high school type attended, i) highest level of high school mathematics, j) job while enrolled, k) enrolment size 2003-04, and 1) percent of minority enrolment 2003-04. Solving the regression required excluding covariates or highly correlated variables causing multicollinearity.

The significant predictor variables $(\mathrm{p}<.05)$ from the hypothesis testing results were gender and enrolment size in 2003-04. The researcher also analyzed standardized beta weights to identify the contribution of each significant variable in predicting the dependent variable. The regression results for female attendees consisted of an odds ratio of 21.80 and a coefficient for dependency of 0.09 . This indicated that female attendees were more likely than were males to earn an associate's degree in engineering and engineering technologies (odds ratio $=21.80, p<$ $.001)$. While it can be concluded from the descriptive statistics that proportionally males and females completed the programs at similar rates $(28.41 \%$ and $30.00 \%)$, females still demonstrated higher rates of completion by $1.59 \%$. The odds results also suggested that, as an institution's enrolment size increases, attendees in engineering and engineering technologies associate degree programs will become completers by 1.00 times $(p<.01)$.

Measures of fitness or likelihood ratios for the regression to predict the completion of engineering and engineering technologies associate's degrees are presented in Table 1.

Table 1: Engineering \& engineering technologies associate's degrees, measures of fitness

\begin{tabular}{lc}
\hline Measures of fitness & Value \\
\hline Negative log-likelihood (Pseudo-R ${ }^{2}$ ) & .27 \\
$\quad-2$ log-likelihood & -111456.20 \\
Log-likelihood, intercept-only model & -81568.2347 \\
Log-likelihood, full-model & .032 \\
Likelihood ratio (Cox \& Snell) & .083 \\
Likelihood ratio (Cox \& Snell) Maximum & .027 \\
Likelihood ratio (Estrella) &
\end{tabular}

Also suggested in Table 1, Cox and Snell's Pseudo $R^{2}(.03)$ and Estrella's Pseudo $R^{2}(.03)$ indicated that the independent variables could explain less than $1 \%$ of the variance in the dependent variable. Based on the model summary statistics, the model demonstrated a weak 
relationship between the predictor variables and the outcome $(\mathrm{p}=.05)$. Given a log-odds completion of .27 and a small weighted sample size, the results of the study are inconclusive in terms of its predictive ability.

\section{DISCUSSION}

Hagedorn and Purnamasari (2012) argued that, to address nuances in STEM-occupational shortages, researchers needed to decouple student background data on STEM courses and programs. In other words, in order to address challenges in the engineering profession, research should start by examining only engineering students. However, few studies focused on students pursuing sub-baccalaureate credentials in engineering and engineering technologies even though the education and training programs are a crucial source of talent and pathway for a STEMcapable workforce.

The demographic makeup of engineering and engineering technologies sub-baccalaureate degree-seeking students in this study mirrored the results of studies of baccalaureate and other graduate engineering students (Buck, Clark, Leslie-Pelecky, Lu, \& Cerda-Lizarraga, 2008; Lichtenstein, McCormick, Sheppard, Puma, 2010; Riegle-Crumb \& King, 2010; Seymour \& Hewitt, 1997). That is, attendees and completers of associate's degree programs in engineering and engineering technologies were predominately White, male, and from a high-income group. The demographic makeup of non-completers of associate's degree programs in engineering and engineering technologies also reflected the results from prior studies of non-completing engineering students pursuing a four-year or advanced degree. Specifically, there was an overrepresentation of non-completers who were legally married, members of a racial/ethnic minority group, and of lower income status (Buck et al., 2008; Lichtenstein et al., 2010; Riegle-Crumb \& King, 2010; Seymour \& Hewitt, 1997). The current study revealed that, proportionally, males and females completed associate's degree programs in engineering and engineering technologies at similar rates as was in previous studies, and supported other research demonstrating no difference between males and females persisting with or departing from STEM higher education programs (Cosentino de Cohen \& Deterding, 2009; Leslie, McClure, \& Oaxaca, 1998; Liu \& Liu, 1999; Sewell \& Shah, 1967).

Added to that, the current study contributes to the overall growing body of evidence of the under-representation of female students entering postsecondary engineering education in the U.S. (Lichtenstein et al., 2010; Lord, Camacho, Layton, Long, Ohland, \& Wasburn, 2009; Cosentino de Cohen \& Deterding, 2009). More notably, the research presents proof of gender disparities at the sub-baccalaureate degree-level. In particular, two distinct, yet equally important, underlying issues can be extracted from these data: low attendance by females, and low numbers of male completers relative to total male attendees. Matriculation by females versus males in associate's degree programs in engineering and engineering technologies was 1:10. This was unfortunate in light of the background information by Wentling and Camacho (2008) that revealed only $10 \%$ of high school females expressed disinterest in engineering. Lord et al. (2009) emphasized a similar observation, as women make up $58 \%$ of all undergraduates, they represent the greatest potential source of engineers.

The second issue related to declining interest in a sub-baccalaureate degree in engineering and engineering technologies was evident in the low completion rates by males. 
Upon closer examination of within-group behaviors, what stands out in the case of male attendees is the low proportion of completers, relative to their higher level of attendance. Carnevale et al. (2011) explained that the low percentages of completion in engineering and engineering technologies relative to matriculation rates could be due to potentially STEMtalented students being diverted to non-STEM educational and career pathways. This divergent gap in the headcount between matriculating and completing sub-baccalaureate students in engineering and engineering technologies was evident in students taking an alternative pathway to an outcome, both of which were not the foci in the present study. One possible explanation from the current data was that males and females alike committed or re-committed to a field or degree goal (i.e., certificate, bachelor's, no degree), which did not include obtaining an associate's degree conferral in engineering and engineering technologies along the way. This finding was consistent with a conclusion by Lichtenstein, Loshbaugh, Claar, Chen, Jackson, and Sheppard (2009) that studied the persistence of students in four-year engineering program. The researchers found that some students did not plan to pursue a career in engineering at the beginning or the end of their undergraduate engineering studies. While the current study did not observe non-completers or interview them about their reasons for non-completion, one explanation could be their choice to study a different subject. However, this contrasted Lord et al. (2009) who found that, during the first two years of college, women were more likely than were men to change their major from engineering to another. Reasons for non-completion in other studies of four-year engineering programs that might warrant further comparison at the two-year level include lack of interest, an overwhelming curriculum, and larger numbers of Physical Science majors (Astin, 1993; Licthenstein et al., 2010; Seymour \& Hewitt, 1994).

While low in attendance numbers, females were more likely than males to earn an associate's degree in engineering \& engineering technologies. This finding raises the subsequent question as to the reasons for this phenomenon. In related studies, female completers in STEM programs attributed their outcome to the positive influence of mentors in education and from the profession or the culture of their program, while others pointed to a greater ratio of female instructors and participation in special programs (Brawner, Camacho, Lord, Long, \& Ohland, 2012; Chang, Sharkness, Hurtado, \& Newman, 2014; Dickerson, 2015; Eris, Chachra, Chen, Sheppard, Ludlow, Rosca, Bailey, \& Toye, 2010; Harris, Rhoads, Walden, Murphy, Meissler, \& Reynolds, 2004; Leslie et al., 1998; Lichtenstein, 2010; Starobin \& Laanan, 2008; Strawn \& Livelybrooks, 2012; Zeldin, \& Pajares, 2000).

Logistic regression results also suggested as an enrolment size increases, attendees in engineering $\&$ engineering technologies associate degree programs will become completers. This is similar to the findings by Miller (2013) who delineated differences in completion rates based on academic program size. Miller (2013) found that chemical engineering doctoral programs with a larger first-year student cohort and overall student and faculty populations experienced significantly higher graduation rates than did smaller programs. Based on Yaghmaee (2014) and Miller (2013), it is plausible that students in this study attended larger colleges that are more urbanized and have more resources that can be used in recruitment, retention, and completion of engineering and engineering technologies programs. On the other hand, Romano and Palmer (2016), Hillman and Orians (2013), and Betts and McFarland (1995) found when reviewing enrolment trends, enrolment size fluctuations coincided with economic upswings and downturns. That is, when there was an economic recession and high unemployment, colleges experienced surges in enrolment. As the economy recovered, enrolment sizes decreased. In 2003, the U.S 
experienced economic growth while enrolments at postsecondary institutions contracted. Then, from 2007-2009 the U.S. fell into an economic recession in which enrolments increased. Given that these business cycles simultaneously occurred during the course of the BPS: 04/09 study, it is possible that the growth in enrolment size since 2003-2004 due to economic conditions also positively impacted completion.

\subsection{Implications}

The few significant variables and their relationship to the statistical model in this study may be circumstantial or conditional given the small sample size and limited variables in the BPS: 04/09 survey to characterize institutional factors. A more accurate instrument that captures the target population of students and institutional sampling of sub-baccalaureate programmes in engineering and engineering technologies is warranted. A study with a larger sample size and includes previously excluded student-related and institutional covariates and extraneous variables may lead to more generalizable conclusions on the completion of sub-baccalaureate programs in engineering and engineering technologies. To increase the predictive model's accuracy, researchers should consider other factors not included in this study and BPS: 04/09 that are known to be factors of persistence in bachelor's and post-baccalaureate engineering degrees (i.e., diversity of instructors, early intervention programs, self-efficacy, job or salary outlook) while retaining gender and enrolment size as independent variables. Extraneous variables (e.g., institutional variants of academic or social integration, motivators, and livedexperiences of specific populations of students [i.e., historically under-represented groups, returning students, students seeking a career change, those pursuing a second degree] enrolled in these programs) are invaluable to understanding careers in engineering \& engineering technologies.

While this research may suit an explanation for a subset of completions in engineering and engineering technologies, future studies should explore the existence of other engineering pathways. Again, the descriptive statistics of 2-year, associate's degree students in engineering and engineering technologies resembled, more so, the participation of students in all of postsecondary education engineering. Given the common characteristics of students pursuing an associate's, bachelor's, and graduate degree in engineering in the U.S., one might visualize the phenomena of associate's degree completion in engineering and engineering technologies by a sub-baccalaureate education-to-profession typology similar to the four-composite typology or four pathways identified by Cannady, Greenwald, and Harris (2014) of STEM Bachelor's degree holders. Cannady et al. (2014) and Lyon, Jafry, and St. Louis (2012) contended that the popularized STEM pipeline and other overly simplistic, compartmentalized frameworks, suggesting a singular route from $A$ to $B$, lacked flexibility and obscured the importance of multiple entry and re-entry points into STEM higher education and professions.

\section{CONCLUSION}

Currently, there is a shortage of qualified engineers and engineering technicians in the U.S. and U.K., and both countries are experiencing low enrolment and low program completion in the sub-baccalaureate education and training programs. Upon closer look, the gender disparities are such that there are low numbers of female starters and low numbers of male completers. The gender disparities are then perpetuated in the engineering industries in the U.S. and U.K.. Given the limited empirical data on 2-year degree completers in engineering and engineering 
technologies in the U.S., the present exploratory study brings greater attention to this population and serves as a starting point for future studies. Early findings from this research already supports early intervention strategies and increased awareness of viable sub-baccalaureate pathways leading to a career or advanced studies in engineering and engineering technologies to meet demands and sustain industries.

This research further demonstrated the complexity involved in investigating the outcome of completion in sub-baccalaureate programs in engineering and engineering technologies irrespective of country. While this part of the study fills a gap in the literature of what is known about engineering and engineering technician students in the U.S., other implications are such that caution should be used going forward when analysing national educational datasets such as BPS: 04/09 to address national workforce shortages. To conclude, this study serves as a starting point for regional, state, and national researchers of education in the examination of engineering and engineering technologies and highlights the need, challenges, and benefits of doing so.

\section{Reference}

Astin, A. W. (1993). Student involvement: A developmental theory for higher education. Journal of College Student Development, 40(5), 518-529.

Astin, A. W. (1991). Assessment for excellence: The philosophy and practice of assessment and evaluation in higher education. Westport, CT: The Oryx Press.

Aud, S., Rathburn, A., Flicker-Wilkinson, S., Krisapovich, P., Wang, X., \& Zhang, J. (2013). The condition of education. Retrieved at http://nces.ed.gov/pubsearch/pubsinfo.asp?pubid=2013037

Betts, J., \& McFarland, L. (1995). Safe port in a storm: The impact of labor market conditions on community college enrollments. The Journal of Human Resources, 30(4), 741-765.

Brawner, C., Camacho, M., Lord, S., Long, R., \& Ohland, M. (2012). Women in industrial engineering: Stereotypes, persistence, and perspectives. Journal of Engineering Education, 101(2), 288-318.

Broene, P. \& Rust, P. (2000). U.S. Department of Education. National Center for Education Statistics. Strengths and limitations of using SUDAAN, Stata, and WesVarPC for computing variances from NCES data sets, Working Paper No. 2000-03. Washington, DC: 2000.

Buck, G., Clark, V., Leslie-Pelecky, D., Lu, Y., \& Cerda-Lizarraga, P. (2008). Examining the cognitive processes used by adolescent girls and women scientists in identifying science role models: A feminist approach. Science Education, 92(4), 688-707.

Cannady, M., Greenwald, E., Harris, K. (2014). Problematizing the STEM pipeline metaphor: Isthe STEM pipeline metaphor serving our students and the STEM workforce? Science Education, 98(3), 443-460.

Carnegie Classification of Institutions of Higher Education. (2017). Basic classification description. Retrieved at http://carnegieclassifications.iu.edu/classification_descriptions/basic.php

Carnevale, A., Smith, N., \& Melton, M. (2011). STEM report. Retrieved at http://cew.georgetown.edu/stem/

Chang, M., Sharkness, J. Hurtado, S., Newman, C. (2014). What matters in college for retaining aspiring scientists and engineers from underrepresented racial groups. J. of Res. in Science Teaching, 51(5), 555-580.

Cosentino de Cohen, C., \& Deterding, N. (2009). Widening the net: National estimates of gender disparities in engineering. Journal of Engineering Education, 98(3), 221-226.

Dickerson, M. S. (2015). A case study of four female electrician technicians in a male-dominated occupation (Doctoral Dissertation). Available from ProQuest Dissertations and Theses. (UMI No. 3739526).

Engineering UK 2016: Synopsis, recommendations and calls for action. (2016). Retrieved at https:/www.engineeringuk.com/media/1309/engineeringuk-report-2016-synopsis.pdf

Eris, O., Chachra, D., Chen, H., Sheppard, S., Ludlow, L., Rosca, C., Bailey, T., Toye, G.(2010). Outcomes of a longitudinal administration of the persistence in engineering survey. J. of Eng. Edu., 99(4), 371-395.

Fayer, Lacey, \& Watson, A. (2017). STEM occupations: Past, present, and future. Retrieved at https://www.bls.govtechnology-engineering-andmathematics-stem-occupations-past-present-and-future/home.htm.

Grant, K. (2015). UK needs over one million new engineers and technicians, says Royal Academy of Engineering. Retrieved at http:/www.independent.co.uk/news/uk/home-news/uk-needs-over-one-million-newengineersand-technicians-says-royal-academy-of-engineering-10334994.html

Vol. 10, No.1| June 2018| ISSN 2229-8932 Journal of Technical Education and Training (JTET) |43 
Greenhoot, A. F., \& Dowsett, C. (2012). Secondary data analysis: An important tool for addressing developmental questions. Journal of Cognition and Development, 13(1), 2-18.

Hagedorn, L. S., \& Purnamasari, A. (2012). A realistic look at STEM and the role of community colleges. Community College Review, 40(2), 145-164.

Harris, B. J., Rhoads, T. R., Walden, S. E., Murphy, T. J., Meissler, R., \& Reynolds, A. (2004). Gender equity in industrial engineering. NWSA Journal, 17(1), 186-193.

Harrison, M. (2012). Jobs and growth: The importance of engineering skills to the UK economy. Retrieved at https://www.raeng.org.uk/publications/reports/jobs-andgrowth

Hillman, N., \& Orians, E. (2013). Community colleges and labor market conditions: How does enrollment demand change relative to local unemployment rates? Research in Higher Education, 54(7), 765-780.

Leslie, L., McClure, G., \& Oaxaca, R. (1998). Women and minorities in science and engineering: A life squence analysis. Journal of Higher Education, 69(3), 239-276.

Lichtenstein, G., Loshbaugh, H. G., Claar, B., Chen, H. L., Jackson, K., Sheppard, S. D. (2009). An engineering major does not (necessarily) an engineering make: Career decision making among undergraduate engineering majors. Journal of Engineering Education, 98(3), 227-234.

Liu, E. \& Liu, R. (1999). An application of Tinto's model at a commuter campus. Education, 119(3), $537-543$.

Lord, S. M., Camacho, M. M., Leyton, R. A., Long, R. A., Ohland, M. W., \& Wasburn, M. H. (2009). Who’s persisting in engineering? A comparative analysis of female and male Asian, Black, Hispanic, Native American, and White students. Journal of Women and Minorities in Science and Engineering, 15, 167-190.

Lyon, G., Jafri, J., \& St. Louis, K. (2012). Beyond the pipeline. Afterschool Matters, 16(1), 48-57.

Miller, A. M. (2013). Timely doctoral completion rates in five fields: A two-part study (DoctoralDissertation). Available from ProQuest Dissertations and Theses. (UMI No. 3604236).

Ministry of Defense partnering with Right Management. (2017). Industry sector guide - Engineering - June 2017. Retrieved at https://www.ctp.org.uk/assets/x/53116

Office of Qualifications and Examinations Regulations. (2015). Qualification and component levels. Retrieved at https://www.gov.uk/ofqual

Planty, M., Hussar, W., Snyder, T., Kena, G., KewalRamani, A., Kemp, J., Bianco, K., Dinkes, R. (2009). The condition of education 2009 (NCES 2009-081). National Center for Education Statistics, Institute of Education Sciences, U.S. Department of Education. Washington, DC.

Riegle-Crumb, C., \& King, B. (2010). Questioning a White male advantage in STEM: Examining disparities in college major by gender and race/ethnicity. Educational Researcher, 39(9), 656-664.

Romano, R., \& Palmer, J. (2016). The community college and the business cycle. Change: The Magazine of Higher Learning, 48(5), 52-57.

Royal Academy of Engineering. (2016). Engineering a future outside of the EU: Securing the best outcome for the UK. Retrieved at https://www.raeng.org.uk/publications/reports/engineering-a-future-outside-the-eu

Sewell, W. H., \& Shah, V. P. (1967). Socioeconomic status, intelligence, and the attainment of higher education. Sociology of Education, 40(1), 1-23.

Seymour, E., \& Hewitt, N. (1997). Talking About Leaving: Why Undergraduates Leave the Sciences. Boulder, CO: Westview.

Starobin, S., \& Laanan, F. (2008). Broadening female participation in Science, Technology, Engineering, and Mathematics: Experiences at community colleges. New Directions for Community Colleges, 142(1), 37-46.

Strawn, C., \& Livelybrooks, D. (2012). A five year university/community college collaboration to build STEM pipeline capacity. Journal of College Science Teaching, 4(6), 47-51.

Tinto, V. (1993). Leaving college: Rethinking the causes and cures of student attrition. Chicago, IL: University of Chicago Press.

U.S. Department of Labor, Bureau of Labor Statistics. (2014). Wind turbine technicians. Occupational Outlook Handbook, 2014-15 Edition. Retrieved at http://www.bls.gov/ooh/installation-maintenance-andrepair/windturbinetechnicians.htm

Wentling, R. M. \& Camacho, C. (2008) Women engineers: Factors and obstacles related to the pursuit of a degree in engineering. Journal of Women and Minorities in Science and Engineering, 14(1), 83118.

Yaghmaee, S. (2014). Predicting Completion Rates at Public Community Colleges in California. Saarbrücken, Germany: LAP LAMBERT Academic Publishing.

Zeldin, A. L., \& Pajares, F. (2000). Against the odds: Self-efficacy beliefs of women in mathematical, scientific, and technological careers. American Education Research Journal, 37, 215-246.

Vol. 10, No.1| June 2018| ISSN 2229-8932 Journal of Technical Education and Training (JTET) | 44 